\title{
Exceptional preservation of tracheal rings in a glyptodont mammal from the Late Pleistocene of Argentina
}

\author{
Martín Zamorano \\ Acta Palaeontologica Polonica 65 (1), 2020: 29-34 doi:https://doi.org/10.4202/app.00654.2019
}

Exceptionally well-preserved material from a fossil mammal is presented. For the first time, several fragments of tracheal rings and cricoid cartilage assigned to Panochthus sp. (Xenarthra; Glyptodontidae) from the Late Pleistocene of Argentina are described in detail and figured. In this contribution, in addition to a meticulous description, a tracheal ring was reconstructed and compared to tracheal rings of domestic and wild mammals. As a result, among domestic mammals it is similar to those of Sus scrofa domestica (domestic pig), and among wild mammals to those of Zalophus californianus (California sea lion). Tracheal rings of fossil vertebrates have been recognized in birds (Cariamiformes and Anseriformes) and other dinosaurs (Theropoda). This is likely the first report of tracheal rings in a fossil mammal; future comparisons with extant xenarthrans could provide information on the paleobiological implications of this structure in glyptodonts, and allow making inferences about other fossil mammals.

Martín Zamorano [marzamorano@fcnym.unlp.edu.ar], División Paleontología de Vertebrados, Museo de La Plata, Facultad de Ciencias Naturales y Museo, Universidad Nacional de La Plata. CONICET. Paseo del Bosque s/n, (1900), La Plata, Buenos Aires, Argentina.

This is an open-access article distributed under the terms of the Creative Commons Attribution License (for details please see creativecommons.org), which permits unrestricted use, distribution, and reproduction in any medium, provided the original author and source are credited. 